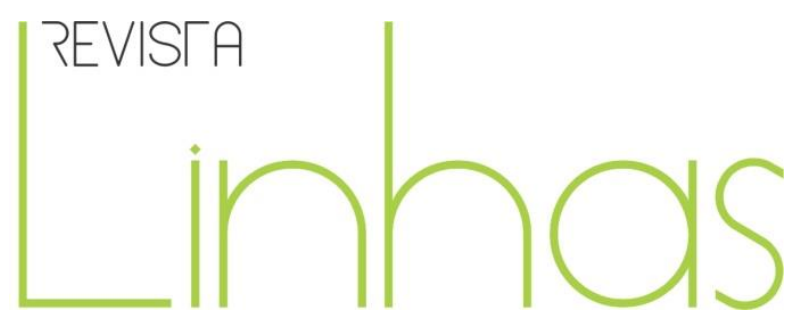

\title{
Produção de narrativas audiovisuais infantis nos anos iniciais: diálogos entre diversidade cultural, formação docente e encontro intergeracional
}

\begin{abstract}
Resumo
O presente artigo é oriundo de uma pesquisa cujo objetivo foi o de promover $\mathrm{o}$ intercâmbio intercultural de narrativas audiovisuais infantis entre duas instituições de educação básica da região da grande Florianópolis. Foi desenvolvida entre os anos de 2014 e 2016, pelo Grupo de Pesquisa Observatório de Práticas Escolares (OPE), da Universidade do Estado de Santa Catarina (UDESC), com financiamento da Coordenação de Aperfeiçoamento de Pessoal de Nível Superior (Capes). Todo o processo da pesquisa desafiou os diferentes sujeitos a compartilharem experiências e aprendizados para além das relações adultos e crianças, ensinantes e aprendentes, tão comum no cotidiano escolar, de modo que conceitos como diversidade cultural, tecnologia, formação de professores, currículo e infância foram criativamente problematizados com o intuito de pautar as ações originais do projeto e atentar aos seus desdobramentos oriundos da complexidade de tais realidades escolares. Este artigo buscou privilegiar os dilemas relacionados a estas temáticas, tomadas como problematizadoras para a formação docente em todos os níveis. Dessa experiência, destacamos a necessidade de os/as professores/as desenvolverem uma escuta mais sensível à diversidade cultural infantil oportunizando protagonismos infantis em múltiplas linguagens. Também apontamos para importância de os cursos de formação de professores/as para a diversidade cultural proporcionarem experiências de pesquisa in loco, diante dos dilemas e tensionamentos perpetrados na contemporaneidade quanto aos papéis de adultos e crianças no contexto das tecnologias digitais.
\end{abstract}

Palavras-chave: Currículo. Professores-Formação. Tecnologia Educacional. Educação Multicultural.

\author{
Juliane Di Paula Queiroz Odinino \\ Faculdade Municipal de Palhoça - \\ Palhoça/SC - Brasil \\ juodinino@yahoo.com.br
}

\section{Geovana Mendonça Mendes- Lunardi}

Universidade do Estado de Santa Catarina - UDESC -

Florianópolis/SC - Brasil geolunardi@gmail.com

\footnotetext{
Para citar este artigo:

ODININO, Juliane Di Paula Queiroz; MENDES-LUNARDI, Geovana Mendonça. Produção de narrativas audiovisuais infantis nos anos iniciais: diálogos entre diversidade cultural, formação docente e encontro intergeracional. Revista Linhas. Florianópolis, v. 19, n. 39, p. 103-122, jan./abr. 2018.
} 


\title{
Production of audiovisual narratives in children in the primary school: dialogues between cultural diversity, teaching training and intergenerational meeting
}

\begin{abstract}
This article comes from a research whose objective was to promote the intercultural exchange of children 's audiovisual narratives between two institutions of basic education in the region of Florianópolis. It was developed between 2014 and 2016 by the Observatory of School Practices (OPE) Research Group of the State University of Santa Catarina (UDESC), with funding from the Coordination of Improvement of Higher Education(Capes). The process of the research challenged the different subjects to share experiences and learning beyond the adult relationship and children, teachers and learners, so common in the daily school life, so that concepts such as cultural diversity, technology, teacher training, curriculum and childhood. This article to privilege the dilemmas related to these themes, taken as problematizing for teacher education at all levels. From this experience, we highlight the need for teachers to develop a more sensitive listening to children's cultural diversity by providing children's protagonism in multiple languages. We also point out the importance of teacher training courses for cultural diversity to provide in loco research experiences in the face of dilemmas and tensions in contemporary times regarding the roles of adults and children in the context of digital Technologies.
\end{abstract}

Keywords: Curriculum. Technology. Childhood. Teacher Education. 
A pesquisa de que trata este artigo enquadra-se no contexto do desafio da inserção das Tecnologias Digitais de Informação e Comunicação (TDIC) pelos professores nas escolas, com a atenção voltada à valorização da diversidade cultural e à garantia da participação ativa das culturas infantis. No centro desta realidade social escolar, emerge a relação entre professores, adultos, e estudantes, crianças e adolescentes, bastante marcada pelos atos de aprender e ensinar do professor, carregados de conteúdo, currículos, didáticas, métodos e tecnologias (LIBÂNEO; ALVES, 2012). Por outro lado, “também são marcados por subjetividades, sentimentos, afecções, percepções, experiências e crenças" (SOUZA-NETO, LUNARDI-MENDES, 2017), o que torna imprescindível a aquisição de habilidades no decorrer do processo formativo que promovam um estreitamento das relações entre os universos de adultos e crianças, crianças e crianças. A pesquisa foi desenvolvida junto a turmas de primeiros anos de duas realidades cotidianas escolares da região da grande Florianópolis, parceiras do projeto maior, vinculado ao Observatório de Práticas Escolares (OPE), a saber, a E.E.B. São Tarcísio, localizada no munícipio de São Bonifácio/SC, região da grande Florianópolis (EBST) e Colégio Aplicação da Universidade do Estado de Santa Catarina (CA) em Florianópolis. No contexto da sociedade globalizada, buscou-se atentar para a diversidade cultural, conferindo uma atenção especial às novas subjetividades infantis mediadas tecnologicamente, potencializadoras de múltiplas e inovadoras expressões culturais. Além das cerca de quarenta crianças, com idades entre 6 e 8 anos de idade, e dos/as profissionais da educação das instituições escolares envolvidas, o estudo contou com a participação de pesquisadoras dos diferentes níveis formativos e de pesquisa vinculadas ao grupo de pesquisa, com os/as quais foram estabelecidas trocas e partilhas de experiências e inquietações acerca do desafio de proporcionar vivências múltiplas e significativas que valorizem a infância, a diversidade por meio do incentivo à ampliação de repertórios culturais, bem como promovam o uso das tecnologias digitais.

No decorrer de todo o processo, muitas questões foram levantadas a respeito: do uso das tecnologias, do papel da escola, do tipo de relação entre professores/as e estudantes a ser constituído, da valorização da diversidade cultural, da defesa da vivência da infância nos anos iniciais entre outros. Sem a pretensão de responder definitivamente estas inquietações, a riqueza da experiência desta pesquisa relacionou-se com a 
oportunidade de realização de trocas entre profissionais de diferentes níveis formativos, todos/as vinculados ao projeto "Tablets, computadores e laptops: análise sobre políticas, infraestrutura e aspectos pedagógicos na inserção de novas tecnologias na escola", coordenado pela professora Geovana Lunardi-Mendes, que consistiu em uma das ações do Programa Observatório da Educação (OBEDUC), desenvolvida pelo Grupo de Pesquisa OPE (Observatório de Práticas Escolares) do Programa de Pós-Graduação em Educação (PPGE) da Universidade do Estado de Santa Catarina (UDESC). O projeto contou com três instituições parceiras, todas adotantes do Projeto Um Computador por Aluno (UCA) ${ }^{1}$, sendo que duas delas já mencionadas participaram da pesquisa de que trata este artigo. Além dos/as bolsistas de graduação e pós-graduação do PPGE, o projeto pôde contar com bolsas de pesquisa para alguns/mas professores/as das respectivas instituições. Assim, as/os profissionais das turmas, as quais a presente pesquisa foi desenvolvida, encontravam-se nesta situação, o que indiscutivelmente favoreceu o comprometimento e o envolvimento da equipe. O objetivo deste projeto maior, no qual a pesquisa se inseriu, consistiu em:

(...) investigar as formas de apropriação pedagógica dos computadores/laptops/tablets em escolas públicas do estado de Santa Catarina, no Ensino Fundamental, atentando para elementos didáticopedagógicos que revelam sua relação com possíveis inovações curriculares durante os processos de ensino e de aprendizagem e, com base neste diagnóstico estabelecer relações entre desempenho nas avaliações nacionais de rendimento escolar. (LUNARDI-MENDES, p. 03-04, 2013)

Como parte deste projeto, foi desenvolvida a pesquisa "Por uma nova compreensão da infância: educação, gênero e diversidade cultural a partir do uso das tecnologias", inicialmente proposta como projeto de estágio pós-doutoral da professora Juliane Di P. Q. Odinino, sendo adaptada ao projeto maior, de modo a envolver a equipe de pesquisadores/as vinculados ao projeto gentilmente conhecido como dos "Tablets".

\footnotetext{
1 O Projeto Um Computador por Aluno (UCA) foi implantado pelo Programa Nacional de Tecnologia Educacional (Prolnfo), em 2007, com o objetivo de intensificar as tecnologias da informação e da comunicação (TIC) nas escolas, por meio da distribuição de computadores portáteis aos alunos da rede pública de ensino. Foi um projeto que complementou as ações do MEC referentes a tecnologias na educação, em especial os laboratórios de informática, produção e disponibilização de objetivos educacionais na internet dentro do Prolnfo Integrado, que promove o uso pedagógico da informática na rede pública de ensino fundamental e médio.
} 


\section{Os caminhos metodológicos}

Neste artigo, enquanto recorte, buscamos destacar o caráter de formação docente justamente pela possibilidade de realização de pesquisa com diferentes sujeitos, dos mais diferentes níveis de formação, que puderam partilhar inquietações a respeito da temática.

Como estratégia metodológica, a pesquisa aqui referenciada com as crianças, lançou mão da observação participante, através da etnografia da imagem e da pesquisaintervenção, a partir do uso e da problematização dos conteúdos midiáticos e da apropriação das tecnologias digitais disponíveis. A atenção esteve voltada para a promoção de trocas interculturais entre as crianças por meio de construções narrativas audiovisuais, produzidas pelas ferramentas tecnológicas ao alcance das crianças nas duas diferentes realidades escolares, como tablets, laptops educacionais e uma câmera filmadora. Esta estratégia, sob a forma de pesquisa-intervenção visou: a) suscitar inovadoras expressões audiovisuais das realidades cotidianas locais infantis; b) promover o intercâmbio de suas inventivas produções simbólicas e culturais infantis, ainda que bastante povoadas e ressignificadas pelos contornos das subjetividades contemporâneas mediadas tecnologicamente; c) atentar para a forma como, no decorrer deste processo, adultos e crianças interagiam, por meio da trocas e partilha de saberes, com a atenção voltada à qualidade destas relações no contexto escolar.

Assim, a pesquisa insere-se no contexto das ações desenvolvidas no OPE pelo estreitamento da articulação com as instituições parceiras, na partilha de informações (junto ao grupo de pesquisa e nos eventos realizados pelo OPE) e no oferecimento de formação docente, na qual participam profissionais das escolas públicas parceiras e pesquisadores da região em todos níveis de formação. Em especial, esta pesquisa buscou promover espaços genuínos de trocas interculturais, tendo em vista os dilemas interpostos quanto aos usos das tecnologias nas realidades escolares, cujas vivências, dinâmicas e memórias nos currículos escolares têm encontrado dificuldades de expressão e questionamento.

O primeiro momento (Etapa 1) da pesquisa de campo consistiu na realização de uma aproximação com as comunidades das instituições escolares, adultos, crianças, a 
partir do uso da etnografia. Em seguida (Etapa 2), a proposta, como pesquisaintervenção, procurou inserir-se nestes contextos com o objetivo de incentivar práticas pedagógicas refletidas que promovessem a abertura e a participação mais efetiva para a circulação e a produção simbólica em diferentes linguagens, recorrendo às tecnologias como potencializadoras deste processo. A partir das produções audiovisuais infantis, o próximo passo (Etapa 3) consistiu na sistematização desse material, com vistas à construção narrativa em forma de filme. A penúltima etapa (Etapa 4), se consolidou no intercâmbio cultural entre as duas escolas envolvidas, em que as crianças puderam assistir às produções de cada grupo de crianças. No decorrer de todo o processo, foram levantadas questões relativas à desconstrução de estereotipias de gênero, classe e etnia, bem como o combate a todo tipo de violência e preconceito. Ao mesmo tempo, buscamos incentivar a valorização das produções culturais infantis, a diversidade e a multiplicidade de formas de expressão. A frequência da visita ao campo aconteceu semanalmente pelo período de, cerca de, um ano.

\section{Produzindo narrativas audiovisuais com as crianças na escola}

A infância é problematizada como categoria central por uma tendência inaugurada nas ciências sociais que procura exaltá-la como experiência calcada na ludicidade, na criação, na invenção e na valorização de suas produções e de seus saberes (ROCHA, 1999). Buscou-se exaltar o modo como os saberes infantis são incorporados na organização dos conhecimentos consolidados na escola, em especial nesta pesquisa, no que concerne aos usos das tecnologias. Tais saberes são circunscritos pelos significados produzidos a partir da construção de formas de poder, experiências e identidades que precisam ser analisadas em seu sentido político-cultural mais amplo (GIROUX; SIMON, 2009, p. 97). Compreendido como artefato social e cultural, os estudos sobre o currículo trazem para o debate as relações de poder implicadas, o qual se configura como área contestada; uma arena política (MOREIRA; SILVA, 2009). Neste horizonte, a disseminação das Tecnologias Digitais da Informação e da Comunicação (TDIC) promoveu uma refração na forma como os saberes se situam e circulam nos contextos escolares, na esteira de uma ressignificação das hierarquias dos conhecimentos e das posições sociais dos sujeitos que compõem o cotidiano da escola. 
O tema da infância tem urgido uma reflexão decorrente das transformações nos cenários econômico, sociocultural e político nos últimos tempos. Entre essas, destacamse: a popularização das mídias e a possibilidade de constituição de múltiplas narrativas e expressões culturais; a importância do universo do consumo midiático nas configurações identitárias infantis; e as mais recentes políticas educacionais, como a obrigatoriedade da matrícula aos quatro anos de idade, o que tem exigido uma ressignificação desta etapa do ensino, aliada à política da ampliação do ensino fundamental para nove anos. Desse modo, a infância tem clamado por uma reflexão a partir de dois principais vieses: de um lado, pela importância do legado geracional conferido ao papel da educação frente às gerações futuras e, de outro, a disseminação dos direitos infantis que clamam ao reconhecimento das crianças como cidadãs e importantes agentes socioculturais no contexto da sociedade contemporânea².

Destaca-se, assim, nas novas subjetividades infantis da contemporaneidade, a centralidade que as mídias e as novas tecnologias usufruem em suas configurações culturais. As tecnologias e os conteúdos midiáticos podem ser tomados tanto como constituintes dos processos de exclusão social, quanto pensadas enquanto possibilidades inovadoras de expressão e afirmação identitárias (BUCKINHAM, 2007). Importante levar em conta o fato de que novas formas de relação social vêm se consolidando como a de “sociedade em rede" (CASTELLS, 1999), pela qual as diferentes culturas se manifestam e operam de forma diferenciada. Com interações mais dialógicas e transformadoras, da rede e das próprias culturas, temos uma compreensão de infância cuja experiência é refratária de inúmeras instâncias sociais que lhe agregam significados. A escola e a creche, as políticas de proteção à infância, a medicina e o universo midiático remetido às crianças, estão entre as principais esferas de atribuição de significados a essa etapa da vida. Neste sentido, a infância é compreendida como um fenômeno social (QVORTRUP, 1994), como uma forma particular de organização social com características históricas e culturais, tomando as crianças, apesar de sua condição social marginalizada e paternalizada, como coconstrutoras da infância e da sociedade.

\footnotetext{
${ }^{2}$ Tal perspectiva apesar de considerar a importância de outras categorias como a família e as escolas, das quais as crianças são supostamente dependentes, tomam as crianças e a infância como centro de análise (QVORTRUP, 1994), inspirando-se prioritariamente no modelo teórico dos novos estudos sobre Sociologia da Infância.
} 
Enquanto sujeito social, a criança deve ser compreendida em seus próprios contextos cotidianos, suas redes de significados locais, no intuito de relacionar à discussão os modos com que exerce agência, se apropriando, tensionando e ressignificando esse universo social endereçado a ela. Assim, a infância pode ser analisada a partir de uma complexa relação entre as práticas do cotidiano e do cotidiano imaginado com que a criança dialoga permanentemente para compreender-se como parte do mundo no qual foi recebida e inserida. Imersa numa rede de significados e relações sociais, aspectos intergeracionais inerentes à análise da categoria infância também são evidenciados, sobretudo em se tratando do contexto escolar, espaço privilegiado de encontro entre adultos e crianças.

Os estudos voltados à compreensão da infância contemporânea têm sido assinalados tanto por uma série de ações e políticas públicas, com ênfase ao papel das tecnologias nas novas subjetividades infantis. Porém, considerar este aspecto implica levar em conta o fato de que uma grande parcela da população encontra-se às margens, sobretudo, dos mais recentes avanços tecnológicos. Desse modo, um dos principais dilemas levantados pelo grupo de pesquisadores nas diversas ocasiões tem a ver com a questão da diversidade e da diferença social que tem reforçado a cultura da desigualdade social no nosso país. Eis uma equação bastante complexa e importante dentro da proposta de se estudar as relações das mídias com os públicos, já que a televisão está presente em $97 \%^{[6]}$ dos lares brasileiros, enquanto que a internet e outros bens tecnológicos como celulares, ipad, tablets, computadores, entre outros, apresentam acesso e uso bastante discrepantes dependendo da realidade social e do contexto cultural. Ainda assim, é possível afirmar que as crianças crescem cercadas por essas tecnologias midiáticas por todos os lados, embora umas com mais acesso e, outras, menos. Porém, os usos e as mediações constituem um importante aspecto para a compreensão da presença dessas mídias e das tecnologias na vida das crianças, as quais podem inclusive sinalizar aspectos relativos à classe social e cultural dos grupos infantis, com impactos em seus modos de ver, de se expressar e de se identificar (MARTINBARBERO, 2001).

Partimos de algumas premissas que sustentam a análise: a) o espaço escolar, como lócus privilegiado da coletividade infantil; b) o papel das mídias na vida desses 
grupos, configurando "uma produção corporativa da infância" como postulam Steinberg e Kincheloe (2001); c) as mídias e as tecnologias como importantes veículos comunicacionais dado seu potencial para a produção de narrativas culturais em que as crianças podem exercer protagonismo, recorrendo a diferentes linguagens.

Em relação às políticas públicas referentes à inserção das tecnologias nas escolas, o que assistimos em nosso país foi uma profusão de iniciativas do Governo Federal proferidas desde os anos de 1990, porém apresentando-se de forma desconexa e descontínua. Tal fragmentação em órgãos e ministérios prejudicou enormemente sua efetividade e alcance da infraestrutura tecnológica nas escolas. Bonilla e Pretto (2015) apostam na formação de professores como forma de garantir uma visão mais horizontalizada do uso das tecnologias.

Tendo em vista a deficiência na formação inicial, destacamos aqui algumas iniciativas que historicamente têm se preocupado com a formação tecnológica continuada, ainda que culturalmente marcada em nosso país pela ideia de aplicabilidade. O Prolnfo de 1997, reformulado em 2007, foi o principal programa de formação continuada de professores para o uso das tecnologias digitais e para disponibilizar laboratórios de informática nas escolas e os núcleos de tecnologia educacional - NTE. Também foi responsável pela incorporação dos ideais de promoção da inclusão digital e da produção de conteúdos digitais educacionais em seus cursos de formação. Outra ação que merece destaque aqui é o Projeto Um Computador por Aluno (UCA), uma política pública federal que articulou instituições em diferentes instâncias - governos estaduais e municipais, universidades, núcleos de tecnologia, escolas, empresas. O UCA, presente nas escolas parceiras envolvidas, carrega uma grande potencialidade para a vivência da cultura digital, não apenas porque em sua concepção o projeto tem como objetivo "criar e socializar novas formas de utilização das tecnologias digitais nas escolas públicas brasileiras, para ampliar o processo de inclusão digital escolar e promover o uso pedagógico das tecnologias de informação e comunicação" (BRASIL, 2009, p. 1), mas, especialmente, pelas dinâmicas e novas práticas culturais possibilitadas pelas tecnologias móveis nos contextos escolares. Porém houve inúmeras falhas na articulação entre as diferentes instâncias envolvidas, o que comprometeu irremediavelmente sua continuidade. Assim, mesmo tendo tido um alto investimento quando criado em 2007, as 
dificuldades enfrentadas marcaram seu fracasso, em 2013, com números insignificantes de alcance de seus objetivos. Conforme afirmam Bonilla e Pretto (2015) acerca do Projeto UCA dentre os desafios e dificuldades enfrentadas, as maiores relacionam-se ao fato de que: "Estas políticas públicas de uso das tecnologias na educação, de uma maneira geral, insistem na perspectiva de tomá-las como ferramentas auxiliares aos processos educacionais" (p. 510).

$\mathrm{Na}$ pesquisa com as crianças, inicialmente o intuito era o de fazer uso exclusivo desses computadores, chamados de uquinhas, para a produção de suas narrativas audiovisuais. Porém, muitos não estavam em condições de serem utilizados, apresentando enormes dificuldades técnicas. Além disso, a partir de relatos dos/as professores/as das respectivas instituições envolvidas no nosso projeto, estes computadores portáteis além de não suportarem informações mais "carregadas", não disponibilizavam programas apropriados para os procedimentos de arquivamento e edição, condições mínimas necessárias para a produção das narrativas audiovisuais.

O debate acerca de qual ferramenta tecnológica seria utilizada foi bastante enriquecedor, pois nos permitiu constatar e discutir em equipe as reais dificuldades vivenciadas nestas realidades escolares. Dentre as conclusões acerca desta discussão, observamos que a aquisição de equipamentos tecnológicos na educação como laptops, tablets, lousas digitais, jogos educativos e sistemas operacionais para as escolas básicas não se limita à melhoria da Educação Básica. Em linhas gerais, a presença das tecnologias não resulta na simples melhoria e qualificação das práticas de ensino e aprendizagem, pois tais tecnologias necessitam primeiramente atender às reais necessidades dos sujeitos escolares, bem como o modo como estes irão se relacionar com tais tecnologias atravessa de forma mais ampla e intensificada o próprio currículo escolar. Assim, a simples decisão de que equipamentos seriam utilizados mobilizou todo um trabalho em equipe, em que pudemos perceber que cada sujeito desfruta de um importante papel na união de saberes para a qualificação desta atividade ou qualquer outra que envolva tecnologias.

Destes momentos de reflexão, vivenciados em conversas com a equipe na própria escola, a pesquisa buscou inserir nos contextos curriculares escolares práticas inovadoras de atuação e intervenção que incitassem a superação, a reflexividade e a resistência 
contra padrões de comportamento disseminados por práticas culturais mecanizadas, tanto do modelo estampado pelos discursos midiáticos, como do ranço da cultura escolar conteudista. A tentativa de rompimento das normatizações, através do estranhamento de estereótipos e de padrões estabelecidos nas culturas infantis vivenciadas na escola, caminhou lado a lado com as propostas de produção das narrativas que questionassem, transgredissem e experimentassem inovadoras e criativas possibilidades de constituição das subjetividades infantis, proporcionadas pelo estreitamento das relações, sobretudo entre adultos e crianças. Para que isso fosse efetivado, foi necessário todo um esforço coletivo na direção de alcançar este objetivo comum, de modo que os profissionais da educação pudessem exercer de forma ativa uma reflexão quanto ao legado geracional no contexto da atual condição infantil.

Tal intervenção nos contextos escolares, também no decorrer de todo o processo, promoveu o exercício de reflexividade sobre as diferentes culturas e discursos que incidem e atuam diretamente no processo de organização curricular frente à atual configuração sociocultural infantil. Na direção do que Moreira (2004) aponta, em se tratando do contexto da escola, foram atentados os objetivos de revisão e questionamento curricular que devem:

(...) procurar desafiar o viés monocultural do currículo escolar, desestabilizar a hegemonia da cultura ocidental no currículo, destacar o caráter relacional e histórico do conhecimento escolar, questionar as representações, as imagens e os interesses expressos em diferentes artefatos culturais, buscando explicitar as relações de poder neles existentes. Nesse enfoque, fazem-se desejáveis programas e currículo que favoreçam ao aluno a crítica de seu ambiente cultural, a familiaridade com distintas formas de expressão culturais, assim como, na medida do possível a produção desses materiais. (MOREIRA, p. 69-70)

Tanto a crítica à ordem estabelecida como o encorajamento de novas produções e de levantamento de repertórios locais, entre saberes e práticas culturais, constituíram-se como a base do que estava por vir. O estreitamento da relação de adultos, educadores/as, e crianças, buscou romper o lugar consagrado do autoritarismo e da reprovação docente, para que fosse possível conhecer mais de perto os códigos 
partilhados presentes nas realidades culturais das respectivas instituições escolares. 0 convite à produção de narrativas audiovisuais infantis que retratassem mais fielmente suas realidades exigiu do/a profissional adulto um reposicionamento de seu lugar, como coadjuvante, porém ao mesmo tempo vigilante quanto ao seu importante papel de educador/a, no combate de práticas que pudessem incitar o ódio, o preconceito, o desrespeito ou a discriminação e, ao mesmo tempo, ser encorajador de experiências enriquecedoras.

Tal experiência evidenciou a necessidade de nós, educadores e/ou em processos formativos, nos questionarmos e revisarmos o papel que desfrutamos no contexto escolar. Enquanto pesquisadores/as e educadores/as em exercício, a oportunidade de estabelecermos este contato com tais realidades revelava como aspectos micro e macrossociais devem ser considerados como fundantes para a constituição dos currículos. Arendt (1995) argumenta que a relação humana com o mundo, mediada pela educação, nunca está dada de antemão, mas tem de ser tecida novamente a cada novo nascimento, no qual vem ao mundo um ser inteiramente novo e distinto de todos os demais. Desse modo, a educação não pode jamais ser entendida como algo dado e pronto, porém tem de ser continuamente repensada em função das transformações do mundo no qual insurgem novos sujeitos e novas realidades. A autora aponta que a crise da educação vivenciada nos novos contextos político e social está relacionada à desvalorização da força da tradição e dos conhecimentos herdados das gerações anteriores, de modo que se busca conjugar o legado científico, humanístico e filosófico com as atuais demandas em torno da diversidade cultural e das múltiplas expressões culturais e artísticas potencializadas pelos veículos comunicacionais, renovados a cada geração.

Todo o processo concernente aos aspectos culturais foi acompanhado da reflexão acerca do papel da escola, com ênfase na maneira como os repertórios locais e as temáticas da diversidade são e podem ser perpetuados através dos saberes produzidos no cotidiano escolar. A partir dos dispositivos tecnológicos, compreendemos que tais conhecimentos podem ser rearranjados por meio de construção de novas narrativas e linguagens audiovisuais, na medida em que as novas tecnologias comunicacionais permitem ultrapassar as barreiras espaciais-temporais, ressignificando identidades e 
borrando as fronteiras da diversidade cultural. Sendo a escola um espaço privilegiado de encontro e de constituição do coletivo infantil, a atenção recaiu a todo o momento para o modo como esse espaço tem contemplado e dialogado a partir de seu modus operandi com os saberes infantis locais mediados tecnologicamente. Tanto as instituições escolares parceiras do projeto, como os/as professores/as bolsistas acompanharam de perto todo o desenvolvimento da pesquisa, e também puderam contribuir com informações relevantes acerca das realidades culturais com as quais conviviam diariamente.

Os estudos críticos e pós-críticos sobre currículo têm questionado o lugar historicamente marcado pela dominação e colonização que resulta na inculcação de conhecimentos e valores cujas práticas são reconhecidas pela violência simbólica (BOURDIEU, 1999). Além de legitimar a exclusão social, tal processo de escolarização irrompe como uma barreira contra outras formas de saberes que não aqueles ditos científicos e técnicos. Este mesmo fenômeno também pode ser constatado nos processos formativos docentes, nos quais há o predomínio dos saberes ditos teóricos, aprendidos em sala de aula. Proporcionar vivências em realidades escolares reais, através da aproximação com os atuais dilemas que implicam na materialização das políticas públicas e remetem aos conflitos cotidianos culturais de geração, de classe e de etnia, podendo ser discutidas, pensadas e encaminhadas coletivamente, foi uma das maiores contribuições desta experiência. De fato, compreendemos que esta proporcionou a todos/as envolvidos/as atentarmos e participarmos com dedicação e reflexividade do movimento de constituição curricular.

Segundo Goodson (2008), o currículo se constrói socialmente na interação dos indivíduos. E como em qualquer interação social, encontram-se lutas, negociações e contradições. Desta forma, compreender esta dinâmica entre o currículo escrito e o praticado faz parte de um esforço de aproximar os efeitos das inter-relações e dos jogos de poder no cotidiano das escolas. Pudemos verificar pela união de esforços, adentrando o universo das culturas infantis, quais códigos e significados partilhados formavam seu sistema social (ORTNER, 1996). Compreender a formação desses sistemas, imbuídos de agência e intencionalidades dos sujeitos, implica reconhecer o leque de possibilidades dentro das complexas redes culturais e sociais nas quais os atores estão imersos. Ortner 
denomina esses sistemas como jogos sérios, devido à imposição das regras sociais externas e à habilidade dos sujeitos de ressignificar, transformar, burlar tais injunções, o que permite pensar que mesmo os sujeitos atravessados por agências semelhantes agem de maneira diferente, transgredindo ou reproduzindo padrões. No contexto da escola, tais jogos encontram-se predominantemente atravessados pelas expectativas de adultos e de outras crianças, meninos ou meninas e apresentam um grau de complexidade de significados que somente um olhar etnográfico fornecerá subsídios para sua interpretação e análise.

Além de sua importância para a compreensão das culturas infantis, conhecer os repertórios midiáticos infantis possibilitou uma aproximação maior junto a esses grupos, tendo em vista o respeito e a seriedade conferidos aos assuntos tão intrinsecamente constituintes das subjetividades contemporâneas das crianças. A presença dos conteúdos midiáticos tem merecido destaque no delineamento das subjetividades contemporâneas, apresentando algumas especificidades em se tratando das culturas infantis, sobretudo pela forma como se endereça às meninas e aos meninos. De olho nas culturas infantis, cabe também investigar e se apropriar da maneira como estas são vivenciadas na escola, enquanto espaço privilegiado de profusão de conhecimentos e vivências culturais infantis.

No processo de construção dessas narrativas infantis, inevitavelmente, surgiram referenciais provenientes da cultura midiática adulta e infantil (BUCKINGHAM, 2007). Reconhecê-los e mapeá-los através de uma escuta sensível e com o auxílio das crianças interlocutoras consistiu numa estratégia importante para a promoção de uma melhor aproximação e quanto à possibilidade de questionamento junto aos grupos pesquisados em contextos escolares.

O processo de construção narrativa pressupõe negociações, questionamentos e subversões, aos quais as crianças costumam apresentar boa aceitação e receptividade. Partiu-se das experiências infantis para, num segundo momento, se propor uma desconstrução e uma desorganização ao sabor das inventividades e criatividades repletas do senso de humor tão característico das crianças. "Narrar a experiência remete ao registro da memória sobre o cotidiano da vida social; ao específico do sujeito; ao coletivo 
de um grupo; aos significados que os sujeitos atribuem aos acontecimentos" (ALMEIDA; VALENTE, 2012).

O intercâmbio cultural entre os diferentes grupos permitiu além da ampliação do contato com diferentes experiências das quais possam derivar aprendizagens de diferentes contextos culturais, também instaurar a promoção e valorização da circularidade desses repertórios no sentido de exaltar e problematizar a diversidade regional, de gênero, de classe social, étnica entre outros. Pretendeu-se conhecer os modos de produção e reprodução cultural das crianças e identificar os processos simbólicos postos em ação no momento de apropriação e reinscrição da cultura do "outro" nos seus próprios modos de conhecer e se comunicar com o real.

A participação de cada pesquisador/a, com destaque às especificidades de suas bagagens de saberes, foi o grande destaque para o sucesso desta pesquisa. Além de consolidar-se como um importante exercício de gestão democrática, esta união de esforços permitiu uma maior aproximação com o grupo de crianças, as quais era nosso objetivo evidenciar. Ainda que tivéssemos críticas quanto aos repertórios culturais midiáticos trazidos pelas crianças, as bolsistas de iniciação científica tiveram um papel fundamental, reconhecido como geracional, na promoção desta aproximação, pelo fato de estarem mais familiarizadas com os conteúdos vividos pelas crianças em seus cotidianos. Vale destacar que as crianças apresentavam, para as constituições de suas narrativas, os conteúdos das mídias de amplo alcance ainda que de maneira ressignificada, com praticamente a mesma frequência com que traziam brincadeiras, entre outras atividades lúdicas de seus repertórios culturais infantis, apresentados em múltiplas linguagens.

\section{Sobre as experiências}

Ao longo da investigação, foram muitas as reflexões estabelecidas com as crianças, entre os pesquisadores e com a comunidade escolar. Muitas vezes, as estratégias precisaram ser revistas e repensadas, como a atividade realizada em uma oportunidade em que se tinha o propósito de assistir às filmagens produzidas junto com as crianças, com o intuito de chamar a atenção para algumas técnicas básicas como 
enquadramento, luz e sombra, movimento da câmera entre outras. Para nossa surpresa, os trechos que seriam considerados como descarte pelos adultos, por não atenderem aos (pré) requisitos de “qualidade técnica" estabelecida, foram aqueles justamente escolhidos pelas crianças de São Bonifácio como os preferidos, por serem inusitados, engraçados, por romperem e transgredirem determinadas normatizações. Ainda preocupando-se com a qualidade da produção, a questão colocada a partir de então seria a de como incorporar tais situações nas narrativas na edição final. Porém, tanto no produto, o vídeo, quanto no decorrer de todo processo de filmagem, a busca orientou-se pela experiência/sentido (LARROSA, 2002), caracterizado como uma abertura e um convite para o desconhecido. Criar as condições para isso requereu uma disponibilidade e "uma passividade feita de paixão, de padecimento, de paciência, de atenção, como uma receptividade primeira, com uma disponibilidade fundamental, como uma abertura essencial” (LARROSA, 2002, p. 24). O tempo passou a ser o grande senhor por ser o responsável pela garantia da experiência como possibilidade de que "algo nos aconteça ou nos toque", como afirma Larrosa, num gesto de interrupção que requer parar para olhar, para pensar, pensar mais devagar, demorar-se nos detalhes, suspender a opinião, o juízo, a vontade, o automatismo da ação, cultivar a atenção e os ouvidos, aprender a lentidão, contemplar a arte do encontro, enfim, dar-se tempo e espaço.

O processo de filmagem para constituição das narrativas midiáticas infantis consolidou-se como uma importante ferramenta de análise, pois pôde ser utilizado também como mais um recurso, dentro da proposta de propiciar um ambiente favorável, para que as crianças pudessem se expressar o mais à vontade possível através de uma proposta lúdica e convidativa. Compreendendo que nos denominados momentos livres, a brincadeira ocupa lugar central na opinião das crianças, também pudemos levar em conta o uso das filmagens a partir do que Claudine de France (1998) pondera referindo às análises dos processos performáticos dentro do trabalho etnográfico com documentação em vídeo. A autora chama a atenção para a importância da escolha metodológica que deve ser feita pelo/a pesquisador/a para o momento da filmagem, a qual não deve se caracterizar por uma postura de ingenuidade. Ao contrário, deve estar atento/a às inúmeras inter-relações manifestas no rito, no caso as brincadeiras, e as interferências ocorridas no próprio processo de filmagem. No entanto, o olhar deve ser direcionado ao que ela denomina matéria-viva, a qual é feita de ordem e de desordens, de espetáculos e 
bastidores (FRANCE , 1998, p. 131). Aqui, o olhar deve estar voltado para o jogo das aparências e das significações visuais presentes em cada momento: nos gestos, nos preparativos, na teatralidade dos corpos, nos objetos, em que o/a próprio/a pesquisador/a configura-se como parte desse processo ritual. Com o objetivo de promover trocas interculturais, teve como desdobramento o levantamento e o registro de características que assinalavam as especificidades de cada grupo, para além das visões escolares estanques e estereotipadas. Também visou garantir a circularidade de saberes em forma de expressões fílmicas, fotográficas, de histórias, de animações, entre outras, na medida em que possibilita o acesso a repertórios culturais diferenciados, além de colocar em voga a diversidade cultural pelo contato com "o outro". Com o propósito de promover as trocas desses materiais entre as crianças, observou-se a riqueza da experiência desse processo como um todo: da construção coletiva de todas as etapas, da captação e produção das imagens à edição. Todas essas etapas remeteram à valorização, à afirmação e ao empoderamento culturais propiciados no decorrer de todo o processo. Enfim, a produção fílmica, ainda que não a etapa mais importante da pesquisa, visou à contribuição do avivamento de memórias e vivências dos repertórios infantis locais, tendo em vista conferir novos significados a partir dos usos de múltiplas linguagens audiovisuais, que pretenderam ser o mais fiel possível às escolhas das crianças.

Finalmente, consideramos que a pesquisa, ainda que tivesse o foco na exaltação das expressões infantis no contexto curricular por intermédio das tecnologias, teve como destaque a ação em equipe de pesquisadores vinculados ao OPE na tentativa de problematizar e pensar coletivamente em estratégias de consolidação de um currículo escolar atento à presença das tecnologias e atuante na defesa da diversidade cultural. Ações como estas endossam o rol de experiências bem-sucedidas que vinculam universidade-escola, ao proporcionar, do ponto de vista da universidade, processos formativos atentos à complexidade das dinâmicas culturais escolares e da perspectiva da escola, uma oportunidade de os/as professores/as em serviço partilharem não apenas suas inquietações e angústias, mas, sobretudo, seus conhecimentos, dentre os quais os saberes de contexto e conhecimentos locais. A atuação de diferentes sujeitos que compõem o cotidiano escolar atuando na busca de soluções para os dilemas contemporâneos que vinculam infância e novas tecnologias no contexto escolar faz com que esta união de esforços favoreça a compreensão dos diferentes aspectos que 
envolvem a complexidade do encontro entre adultos e crianças. Todo este processo, mais do que o produto em si, no caso a produção das narrativas infantis, clamou pela constante reflexão quanto ao papel da escola na contemporaneidade, tendo em vista os tensionamentos promovidos pelos lugares sociais de adultos e crianças frente às novas tecnologias. Das reflexões levantadas nas diversas oportunidades de estudo pela equipe, destacamos a importância de conciliar o legado científico e ético, próprio das gerações anteriores, aos novos desafios das gerações mais novas, para as quais a presença das tecnologias é constituinte de suas realidades culturais. 


\section{Referências}

ALMEIDA. Maria E. B.; VALENTE, José A. Integração currículo e tecnologias e a produção de narrativas digitais. Currículo sem Fronteiras, v. 12, n. 3, p. 57-82, set./dez. 2012.

ARENDT, Hannah. Entre o passado e o futuro. São Paulo: Perspectiva, 1995.

ASCH, Timothy. Porque e como os filmes são feitos. In: Cadernos de Antropologia e Imagem. RJ: NAI/UERJ n. 3, p. 85-98, 2003.

BABHA, Homi. O local da cultura. Belo Horizonte: Editora UFMG, 1998.

BONILLA, Maria Helena; PRETTO, Nelson. Política educativa e cultura digital: entre práticas escolares e práticas sociais. Perspectiva, Florianópolis, v. 33, n. 2, p. 499-521, maio/ago. 2015.

BOURDIEU, Pierre. A miséria do mundo. In: NOGUEIRA, M. A.; CATANI, M. (Orgs). Escritos de educação. Petrópolis: Vozes, 1999.

BUCKINGHAM, David. Crescer na era das mídias eletrônicas. Tradução: Gilka Girardello e Isabel Orofino. São Paulo, Loyola, 2007.

CASTELLS, Manuel. A sociedade em rede. São Paulo: Paz e Terra, 1999.

DUARTE, Rita Maria Ribes, SALGADO, Raquel; SOUZA, Solange Jobim. Pesquisando infância e televisão: algumas considerações teórico-metodológicas. In: ENCONTRO ANUAL DA ANPED, $25^{\circ}$ Caxambu, MG: 29/9 a 2/10 2002 Anais. Caxambu, MG: Grupo de Trabalho Educação e Comunicação, 2002. , p. 55-71.

FRANCE, Claudine. Cinema e Antropologia. In FRANCE, Claudine. Técnicas materiais e técnicas rituais. Campinas: Unicamp, 1998.

GIROUX, Henri.; SIMON, Roger. Cultura Popular e Pedagogia Crítica: a vida cotidiana como base para o conhecimento curricular. In: MOREIRA, A. F. B.; SILVA, T. T. da (Orgs.). Currículo, Cultura e Sociedade. São Paulo: Cortez. p. 93-194.

GOODSON, Igor F. As políticas de currículo e de escolarização: abordagens históricas. Trad. Vera Joscelyne. Petrópolis, RJ: Vozes, 2008.

LARROSA, Jorge. Notas sobre a experiência e o saber de experiência. Revista Brasileira de Educação, n. 19, p. 20-28, 2002.

LIBÂNEO, José Carlos; ALVES, Nilda (Orgs.). Temas de pedagogia: diálogos entre didática e currículo. São Paulo: Cortez, 2012.

LUNARDI-MENDES, Geovana Mendonça. Aulas conectadas? mudanças curriculares e aprendizagem colaborativa entre as escolas do Projeto UCA em Santa Catarina. Projeto de Pesquisa. Florianópolis: Secretaria de Estado da Educação, 2013. 
MARTIN-BARBERO, Jesús. Desafios Culturais: da comunicação à educomunicação. In: CITELLI, Adilson et al. Educomunicação: construindo uma nova área de conhecimento. São Paulo: Paulinas, 2011.

MOREIRA, Antonio; SILVA, Tomaz Tadeu. Sociologia e teoria crítica do currículo: uma introdução In:MOREIRA, Antonio; SILVA, Tomaz Tadeu (Orgs). Currículo, cultura e sociedade. 11 ed. São Paulo: Cortez, 2009.

ORTNER, Sherry. Making Gender: the politics and erotics of culture. Boston: Beacon Press, 1996.

QVORTRUP, Jens. Childhood matters: an introduction. In: QVORTRUP, J. et al. (Eds.). Childhood matters: social theory, practice and politics. Avebury: Aldershot, 1994.

ROCHA, Eloísa Acires Candal. A pesquisa em educação infantil: trajetória recente e perspectiva de consolidação de uma pedagogia da educação infantil. 1999. Tese (Doutorado em Educação) - Unicamp, Campinas, 1999.

SARMENTO, Manuel Jacinto. Gerações e Alteridade: interrogações a partir da sociologia da infância. Revista Educação \& Sociedade, Campinas, v. 26, n. 91, p. 361-378, maio/ago. 2005 .

SOUZA-NETO, Alaim. LUNARDI-MENDES, Geovana Mendonça. O uso das tecnologias digitais na escola: Discussões em torno da fluência digital e segurança docente. Revista eCurriculum, São Paulo, v. 15, n. 2, p. 504-523 abr.jun., 2017.

STEINBERG, Shirley.; KINCHELOE, Joe. (Orgs.). Cultura infantil: a construção corporativa da infância. Rio de Janeiro: Civilização Brasileira, 2001. 